\title{
SURF RHETORIC IN AMERICAN AND BRITISH SURFING MAGAZINES \\ BETWEEN 1965 AND 1976. ${ }^{1}$ \\ JOAN ORMROD
}

\section{Manchester Metropolitan University}

The spread of surfing has been linked with the ways nations from around the globe have been influenced by 'Americanization'; the influence of American culture as the prevailing global culture on the local culture. ${ }^{2}$ Appadurai's work on the different ways that globalization is disseminated has formed a significant model for the debate about the dissemination of sport. ${ }^{3}$ Appadurai (1990) suggests several ways that global culture is disseminated including mediascapes in which mass media spread global texts. ${ }^{4}$ Often these global texts are regarded as expressions of wish fulfilment by appealing to audiences' dreams:

More people in more parts of the world dream of and consider a greater range of possible lives than they have ever done before...Increasing numbers of people world-wide are bombarded by global imagination industries 'version of glittering, enticing commodity forms of possible lives. ${ }^{5}$

American surfing narratives represented in surfing magazines and 'pure' surf films are examples of this notion of the 'dream' scenario. The surfers in these texts venture forth into unknown territories experience the unspoiled beauty of exotic locations and surf in perfect waves and warm waters. However, how are these dream scenarios received in surfing nations which differ from American culture? Booth's work on Australian surfing suggests the surfing subcultures adapt their values dependent upon national agendas. This research, part of a wider study ${ }^{6}$, examines how 
American surfing rhetoric was received by British surfers between 1965 and 1976 . Unlike American surfers who romanticised the wave as an act which reflected the conquering of new territories, British surfers articulated quite a different set of values, dreams evoked by mass media and subcultural representations that proposed, 'The individual is both actor and audience in his own drama...he constructed it, stars in it, and constitutes the sum total of the audience. ${ }^{7}$ British surfers of the early seventies enacted a fantasy involving adventure. What is significantly different about British surf rhetoric is that surfers attempt to inform about the hardships as well as the pleasures; one experiences the hardship to increase the pleasure. This notion of the hero enduring hardships on an adventure to conquer overwhelming odds could be regarded as 'typically' British.

\section{American and British surfing}

Surfing arrived in America from the Pacific Islands in the early twentieth century mainly as a result of the exotic appeal of Hawaii as a tourist destination. After World War Two American surfing became a commodity-based subculture popular with affluent, mainly middle class, white youth. ${ }^{8}$ It was popularised with the advent of the Malibu surfboard in the early 1950s. Malibu boards were made from foam and were cheaper to manufacture, lighter and easier to surf than balsa wood boards. Surfing became a teenage craze from the late fifties through the production of exploitation films such as Gidget (1959) and Beach Party (1963) and the pop music of the Beach Boys and Jan and Dean. This mass media exploitation promoted the hedonistic surfer lifestyle and notions of surfing as a youthful activity around the world. ${ }^{9}$ Consequently until the mid 1960s Malibu surfing which was predicated upon 'hot-dogging' (performing stunts on the surfboard), Malibu surfboards and the hedonistic, leisure- 
based, surfer lifestyle created the stereotype of the 'bleached blond, bronzed surfie' in the popular imagination. ${ }^{10}$ Through this brief description of American surfing history it is possible to identify its construction through tourism, leisure, capitalism and youth culture. Tourism is especially significant in this discussion as, by the end of the 1960s the search for the perfect wave and surfaris which were constant features of the surf press and 'pure' surf films ${ }^{11}$, had become central to surf fantasy lifestyle. ${ }^{12}$

The similarities and differences between American and British surf rhetoric it is proposed arise from nationalist rhetoric encapsulated in British rhetoric through climate and surfer identity. Modern British surfing did not become widespread until the Surf Lifesaving Association of Australia (SLSAA) formed a surf lifesaving club in Bude, North Cornwall in 1954. Surf Lifesaving clubs spread along the English south coast and into South Wales by the early sixties thanks to the activities of members who gave lifesaving demonstrations and surfing demonstrations on the beaches. Like the SLSAA part of the Surf Lifesaving Association of Great Britain's activities involved the use of surfboards, hollow boards in the fifties and Malibu boards in the early sixties. They were used as lifesaving craft but also a form of exotic entertainment when the surf lifeguards gave spectacular night time surfing displays. Large tourist audiences at the Newquay resort in Cornwall were attracted to night time displays of surfers 'towed behind speedboats, wearing capes and carrying blazing torches'. ${ }^{13}$ From the early sixties through the introduction of Malibu boards and the music of the Beach Boys, Californian surf values developed in British surfing. This exacerbated a split between the SLSA of Great Britain and surfers who wished to surf for pleasure rather than the discipline of beach patrols and surf lifesaving. In 1966 some surfers formed the British Surfing Association (BSA). The BSA aimed to develop British surf technique and introduced rules and regulations to competition in 
addition to surf schools on the beaches to train would-be surfers. By the mid 1960s although British surfing was beginning to develop its own subcultural identities, it did not have the long history of American and Australian surfing. So in an era when American and Australian surfers were consolidating their places in the global surfing scene, British surfers were intent upon developing a national surfing identity and this was constantly promoted in British surfing magazines. This article examines the types of rhetoric articulated in American surfing magazines comparing it with that expressed in British surfing magazines.

\section{Surfing magazine rhetoric}

Analysis of surfing magazines has been a fruitful method of research in surfing as they are written by surfers for surfers and therefore can be expected to articulate the subcultural concerns of an era. This enables the researcher to identify key issues in surfers' values and motivations from an inside perspective. Surf magazines have been analysed in studies of localism, ${ }^{14}$ motivations and values, ${ }^{15}$ gender ${ }^{16}$ and subcultural authenticity. ${ }^{17}$ This article limits the analysis to a comparison of British with American surf literature as American magazines were more widely read by British surfers. ${ }^{18}$ Two American magazines, Surfer and Surfing, were analysed. Through the comparison this article identifies to what extent British surfers consumed the fantasy surfing lifestyle encoded within American magazine rhetoric and the differences which tended to be articulated through issues of place, localism and climate.

Surfer and Surfing promoted a fantasy, idealised lifestyle predicated on travel and the pleasure of surfing perfect waves. Notions of Surfer as a magazine promoting a fantasy lifestyle were proposed by its originator, John Severson, who described it as, '...a dream magazine. I saw that right away. The perfect surf, the faraway places...we all dream about the same things. ${ }^{, 19}$ Severson and his succeeding editor, 
Patrick McNulty attempted to promote the clean side of surfing in editorials which proclaimed against drugs taking and anti-social behaviour. ${ }^{20}$ Surfer was so successful that by the mid sixties it was regarded as the 'surfer's bible'. Its main rival, Surfing was first published from 1964 and was aimed at a younger audience. Therefore there were articles for the beginner about surfboard design and surf technique. Like Surfer, Surfing promoted a fantasy lifestyle from the beginning of its publication. In its twentieth anniversary issue, Chris Carter described how Surfing, 'indulged my wildest fantasies ${ }^{21}$ and it was, 'the recorder and embellisher of this fantasy lifestyle'. ${ }^{22}$ Both magazines featured articles and interviews with, by and about star surfers, readers' letters, travel articles about surfaris, surf film reviews, short stories, pictures of surf spots and waves. Surfer and Surfing promoted surfing as a leisure-based activity, based on play and youthful values. From 1968-1971 the 'work-is-play' drop out philosophy of soul surfing, surfing for spiritual reasons was adopted when Drew Kampion became editor ${ }^{23}$. Kampion infused the magazine with countercultural values, attacking contests, introducing environmental features, making references to drugs and stressing the romance of the wave in poetry and fiction.

\section{British surfing magazines}

In the absence of any regularly published national surfing magazines until 1969, Britain, Surfer and Surfing were major sources of information. The two magazines were available through surf shops which were mainly located in surf shops on the South coast of England or South Wales. Alternatively a surfer might take out a subscription. Consequently they were significant in the development of British surfing as it was through them that British surfers were informed of new surf techniques and surfboard design and technology. Each magazine issue was circulated amongst surf club members or friends as one interviewee noted, '... this [was a] completely 
different world that we weren't used to, but it was something that we...desperately wanted.' It might therefore be supposed that as British surfers knew no better they would adopt the romanticised image and fantasy lifestyle represented in American surfing magazines. This, however, was not the case. British surf magazines expressed a number of differing responses to the values proposed in American magazines. These ranged from adopting the dominant encoded values to expressing oppositional values. $^{24}$

Three British surfing magazines are analysed in this article, Surfing UK, British Surfer and Surf. They are supplemented by writing in the Edinburgh surf club newsletter, Point Break. Surfing UK and British Surfer were published in 1969, the former lasted four issues, the latter six. Both suffered from a lack of quality articles and photographs. In describing British Surfer Thomson, for instance, notes, 'The editor is always in search of good copy - including photographs that are in sharp focus!' ${ }^{25}$ It was not until 1974 that a regular British surfing magazine, Surf, appeared, edited by Bez Newton who surfed in North Wales. Surf was published regularly between 1974-8 but like its forebears it suffered from a lack of quality material. Consequently the number of pages differed from month to month and was dependent upon contributions from editorial staff or the number of distractions in the shape of surfaris or good surfing. It had a circulation of 1,300 over the United Kingdom and Australia. ${ }^{26}$ In an estimated population of 3000 British surfers at this time, ${ }^{27}$ Surf $\underline{\text { could, therefore, be said to have good coverage. }}$

British magazines could not compare with the production values of their American counterparts. Although British Surfer and UK Surfing were glossies, Surf began as a simple photocopied publication stapled together. By 1978 Surf was being published with a simple two-colour front cover. Regular articles in Surf consisted of 
interviews with influential British surfers such as Roger Mansfield, Chris Jones, Tigger Newlings and Nigel Semmens. There were at least three regular series on travel or exotic waves and the surfari such as 'Surf Spots', 'Truckin', 'Impressions'. Every issue contained the latest contest and competition news and surf club information. More erratic topics were short stories, surf verse, film reviews, music reviews and skateboarding articles. However apart from two issues Surf did not feature readers' letters.

As discussed above, American magazine rhetoric became charged with countercultural rhetoric from the mid to late sixties. Soul surfing rhetoric is now discussed to contextualise the discussion on how British surfers responded to these romanticized myths.

\section{Hippie and soul surfing rhetoric}

Soul surfers promoted, 'alternate, typically utopian, lifestyles and political activism...They rejected high consumption, materialism and competition, and they expounded a form of "fraternal" individualism that extolled creativity and selfexpression'. ${ }^{28}$ These values are clearly influenced by hippie counterculture which stressed rural over urban locations, feeling and intuition over logic, and escapism whether to the land, on a spiritual quest to the Orient ${ }^{29}$ or in the mind.$^{30}$ Hippies emerged as a response to urbanisation, disenchantment with technology and alienation from the stifling conformity of post World War Two culture in the developed world. It was also a response to the growing numbers of young people who entered higher education in industrialised and more affluent nations and their consequent involvement in 'new left politics'. ${ }^{31}$ 'New left politics' tended to be middle class based $^{32}$ and encouraged the growth of alternate lifestyles which blurred the boundaries between work and leisure. 
Brake proposes six themes in hippie values: passive resistance, individualism, movement, dissociation, expressivity and subjectivity. ${ }^{33}$ These were extensions of middle class values, 'for example, subjectivity and 'doing your own thing' could be seen as a hippy [SIC] 'stretched value' of the middle-class evaluation of individualism and self-growth.' ${ }^{34}$ In surfing, 'doing your own thing' in the late 1960s and early seventies might be identified in the 'expression session' where surfers expressed their creativity on the wave. The translation of hippie values in soul surfing is shown in Figure 1: INSERT TABLE HERE

Figure 1 Adapted from Mike Brake, Comparative Youth culture: the sociology of youth culture and youth subcultures in America, Britain and Canada. London, New York; Routledge, (1990), pp.99-102.

From the mid sixties surfers' fantasy retreat became a retreat from reality with the advent of the short board which enabled them to access previously almost impossible tube waves. The tube wave curled over forming a hollow through which the surfer would travel. Once inside surfers reported a sense of peace and time seemed to stand still. In the 1973 pure surf film, The Crystal Voyager, George Greenough, a Californian kneeboarder and surf guru, proclaimed, 'You might only be in there for a few seconds of time, but in your head it goes on for hours...It's a time-warp when you're inside the wave... The only reality is what's happening right there.' Soul surfers claimed they became involved with the wave and the wave was a means for them to express their creativity in an artistic decision. ${ }^{35}$ Waves were described as 'dreams, playgrounds, podia and even asylums'. ${ }^{36}$ The experience of the tube ride was often likened to an 'altered state' and akin to experiencing an acid trip. From the late sixties drugs became part of the everyday experience of surfing. According to Kampion the nomadic lifestyle and freedom loving attitude of surfers, 'put them 
[surfers] in the right place at the right time to participate in some entrepreneurial ebb and flow. ${ }^{37}$ Drugs were in common usage in the surfing community in American and Australian surfing cultures in the early 1970s, although Warshaw argues that this was no more than in other youth subcultures. ${ }^{38}$ The most common drugs taken were marijuana, although LSD and heroin were also used. World champion, Nat Young, for instance, recorded an experience of a tube ride whilst high on magic mushrooms, reasoning that the ancients took drugs to experience visions ${ }^{39}$ It was therefore unsurprising that surf rhetoric should include allusions to drug altered states. An article by Gary Crandell for instance stated that, by surfing, '...one is riding the thin edge of reality'. ${ }^{40}$ As a response to soul surfing and hippie values in surfing, from the late sixties 'green room' writing emerged in magazines. The term was coined following an interview with Jock Sutherland, the foremost tube rider of the late sixties in Surfer. Sutherland described the inside of a tube wave as 'the pope's living room' ${ }^{41}$ 'Green room writing' often took the form of non-scanning poetry, descriptive travel prose or whimsical fiction and described the spiritual and aesthetic aspects of the wave. A letter in Surfer allied green room writing with drug taking, 'Most of us know Queen Jane loosened things up...but no one would be expected to empathise with those-who-have-dwelled-in-the-green-cathedrals unless he goes there himself, so why kid ourselves?.'42

Typical examples of green room writing suggested, safety and a retreat from the ills of consumerism and modern life in the wave as in the following examples: 'If only the plastic world of price tag values would pause and be aware... and savor [SIC] the full essence of a wave... and revolve in our kaleidoscope of colors [SIC] and sun patterns...then they too could know our essence of a moment. ${ }^{\text {,4; }}$ 'Within a cavern of 
peace, a silent hissing, crystal shingles of green perfection, and you're safe, but locked far and deep within the hole of danger. ${ }^{, 44}$

Against this fantasy scenario the remainder of the article now compares the reception of British surfers to American surf rhetoric. It begins by discussing areas of crossover in green room writing where British surfers receive messages encoded in American surf magazines. It then goes on to discuss areas which differ. The themes in these areas tend to be the result of nationalist rhetoric which links British surfing identity with location, climate, localism and a realistic appraisal of the surfari experience. The latter challenges the assumption of fraternal bonding constantly expressed in surf magazines as it identifies conflict in surfing particularly where hierarchies on the wave were transgressed. ${ }^{45}$

As discussed above, British surfers were dependent upon American surfing magazines and films for their information about surfing. So to what extent did 'green room' writing and soul surfing values penetrate and affect British surf rhetoric? Certainly hippie rhetoric influenced descriptions of the perfect wave in poetry and prose with themes similar to those of American and Australian magazines discussed above. Noting the spiritual and potentially altered state of the tube, British Champion, Roger Mansfield, declared, '...the whole essential purpose of surfing today is to get tubed. Once you've been tubed properly it affects your whole life...because getting tubed is an out-of-the-body experience, an experience that will affect your entire lifetime, a spiritual experience... ${ }^{46}$ This seems a similar sentiment to Lyng's notion of a feeling of oneness with their environment felt by edgeworkers. It is an experience of the body which is lost to words and lives for sensations, which as discussed above, opens the surfer up to the world. ${ }^{47}$ An article in Surf proposes surfing as, '... a spiritual encounter...Surfing is merely another sport to those who have not 
experienced being locked into a shimmering, cascading, moving tube of water. ${ }^{48}$ So far the writer imitates American green room writing. However, he then qualifies his statement, 'Surfers will go to extreme lengths to catch a wave, braving freezing conditions, dangerous reefs and rocks, powerful currents, sharks and insane crowds...They will drop out of established careers to be free to surf, give up material pursuits in favour of the sea... ${ }^{49}$ The spiritual encounter with the sublime in nature is qualified by the intrusion of reality in the form of danger and inhospitable conditions, issues that consistently recur in British surf rhetoric. This sentiment was reiterated by a Scottish surfer who suggested, '...the drugs and the drinking and the bad behaviour that went with it in some parts...never happened up here - there weren't enough people and it was too damn cold' ${ }^{50}$

British surfers tended to be quite clear on the differences between themselves and American or Australian surfers, '...we are surfers who like to surf without a permanently blocked mind - unlike most of the Aussie and Yankee surfers who crowded this place [Spain]. ${ }^{51}$ Consequently, romanticised green room poetry and fantasy did not always meet with approval. A typical cynical response to the poetry and fiction was written in a letter to British Surfer, 'Please no more rhapsodies about surfing in verse, that don't even scan. Besides being an offence to the eye they tell nothing to the reader about the actual facts and figures of surfing in Britain. ${ }^{52}$ British surfers tended to believe it was necessary to improve their national profile and expertise and to develop the surfing community than romance the wave in verse. Much British rhetoric tended to promote a realistic rather than a romantic approach to the surfing lifestyle, this had much to do with a desire to promote British national surfing identity. From its earliest publication Surf attempted to fulfil its goal of uniting a cohesive British surfing identity set out in an editorial by Bez Newton who 
proclaimed the magazine was, 'a truly national surfing journal' ${ }^{53}$ It attempted to achieve national cohesion by encouraging its readers to discover new surf spots around the United Kingdom and in Europe or good humouredly insulting other surfing nationals. One major difference identified between American and Australian surfing and British surfing was in the climate. This was constantly discussed and identified as a defining feature of British surfing. Newton also proposed that the temperature and dedication necessary to surf in Britain as key factors in the superiority British surfers over other nationals:

British surfers, we believe, are the best in the world - oh, they may not show so well in international competitions - but they are 'best' in this sense: no other surfing nation has to put up with the cold and off-putting conditions that are our daily lot...our surfers are best in that they are keenest. It's easy...to get a wave every day if you live in Burleigh or on Maui: it's much tougher if you live in Rhosneigr or Tynemouth or East Runton. It's easy to get good if your address is Pacific Coast Highway, Malibu, California: not so easy if it's Telford, Salop - you nearest surf is well over 100 miles away, and...when you wake up stiff on Saturday mornings after a mad drive on Friday night it's flat or blown out. ${ }^{54}$

What is significantly different about British surf rhetoric is that surfers attempted to inform about the hardships as well as the pleasures; one experiences the hardship to increase the pleasure. This could be regarded as a 'typical' British attitude, the hero enduring hardship on the adventure to conquer overwhelming odds. This spirit of adventure was one of the themes of the surfari and related, in part, to American surfari rhetoric. 


\section{Surfaris and travel}

There were three main reasons which American surfers gave to travel; nationalist myths of expansion, cheap airfares and overcrowding of waves. As mentioned above, surfing developed and was diffused around the globe as part of tourist discourse. From the early twentieth century American surfers would stow away on boats travelling to Hawaii as a 'rite of passage'. Air fares continued to fall during the twentieth century until the 1970s. An economy fare from America to Honolulu in the '960s was one hundred and ten dollars. In 1970 a thrift fare to Honolulu had fallen to eighty-five dollars. By the mid 1970s this price had risen to one hundred and twentyfive dollars. ${ }^{55}$ Therefore when Malibu waves became overcrowded in the early sixties it is unsurprising that dedicated surfers turned their eyes towards other surf spots in the world such as Australia and South Africa. 'Pure' surf film narratives in this era, such as Albert Falzon's Morning of the Earth (1972), often featured unknown or exotic surf spots. ${ }^{56}$ The most famous of these, Bruce Brown's The Endless Summer (1964) tells how, with $\$ 60,000$, he and two Californian surfers, Robert August and Mike Hynson, travelled around the world to follow an endless summer and ride the

perfect wave. ${ }^{57}$ The notion of escape to a pastoral Eden and the elusive 'perfect wave' crystallising its place as the organising myth of surf culture. ${ }^{58}$ 'Mexico Malibu', in Surfer 1965 is typical of the romanticisation of the surfari as it is written as a typical quest or detective story, 'There have always been many myths of huge green waves, undiscovered spots, perfect breaks abounding in Mexico. But like the El Dorado sought by the ancient Spanish conquistadores, the treasure is always over the next hill, beyond the distant jungle. ${ }^{59}$ What is significant about this story is that it is a quest, but a quest to discover the known rather than the unknown, to discover a wave like Malibu. As Warshaw suggests: 
For many surfers...the real search for the perfect wave has been less to do with adventure, romance, and the pursuit of new experiences and more with just getting the hell away... Surfers on the road didn't look for anything particularly different. They wanted Malibu (or Kirra, or Grajagan, etc) without the crowds'. ${ }^{60}$

Once a holiday destination was identified as desirable, however, the impact of tourism could spoil the escape from the crowds. Similarly, popular surf spots quickly became crowded. By the mid sixties, Surfer had resorted to keeping secret the locations of some hot spots.

\section{British surfaris}

From the mid sixties British surfers either explored the largely unsurfed British coast or paid for a packaged surfing holiday which could be arranged through various companies based in Bideford, Sennen, Widemouth Bay and St. Agnes. In St. Agnes, 'Surfing Safari’ arranged surfing holidays for $£ 25$ per week. This paid for residence in a local guest house, breakfast and evening meal and packed lunches. Transport to beaches around the coast in a Land Rover was arranged, a surfboard and wax were provided along with a wet suit between October and March. ${ }^{61}$

By the early seventies the growth of the tourist industry and increasingly cheap travel abroad, encouraged British surfers to venture to Biarritz in France, Portugal and Morocco. However, rather than take an organised package holiday, British surfers tended to drive to the continent, usually as part of a group from a surf club, or by advertising for interested parties to hire a minibus. For instance The Spinner Surf

Shop, St. Agnes made regular trips to Biarritz in the autumn and winter. ${ }^{62}$ To discover warmer waves British surfers travelled further south to Biarritz and Portugal as the sixties turned into the seventies. Even in warmer climes reporting was realistic rather 
than romantic. A trip to Morocco, in 1974, describes the, 'sky still overcast, and you're still shattered after the long drive from Agadir'. ${ }^{63}$

British surfers travelled for a number of reasons; prohibitions in popular surfing beaches of Cornwall and Devon, crowding, which often lead to localism, quality of waves, adventure and climate. Local councils in resorts such as Newquay were concerned with possible injury to holiday makers or other surfers should a surfer have a wipe-out or lose control of their board. Newquay town council therefore took measures to control surfers by roping off an area specifically for surfing and requiring surfers to register their surfboards for the sum of eight shillings and sixpence. ${ }^{64}$ An irate surfer complained, 'Newquay...council just don't want surfers...[therefore they are] closing beaches because of the danger. ${ }^{65}$

British surfers were inspired by either surf magazines or films to travel to more exotic climes. Like American surf locations, once a wave was identified it became overcrowded. Consequently, good surf locations were either not named or given an ambiguous name. For instance, in a Surf magazine interview with a British surf champion, Roger Mansfield, he discussed keeping secret the name of a surf spot in Spain, 'I suppose its worth withholding the name of the place if it keeps some of the Yanks and Aussies away, keeps it from getting commercialised. ${ }^{66}$ Despite the attempt to withhold the location one writer noted how his surfing fraternity travelled to Spain their appetites 'whetted by 'We'd heard about That Place; we'd read stories about That Place. Neither the stories, the words nor [SIC] the blue-green images said enough. Yet these were the things that whetted our appetites. ${ }^{97}$ The colour, temperature and quality of waves of 'That Place', no doubt were a great draw for British surfers. 
Quality of waves was also given as a reason for travel. Bez Newton writing for Surf noted, 'There's no comparison [with Australian surf] because Australian surf is just more juicy. It's bigger, it's faster: you can do a lot more in Australian surf. You haven't got the sections here: you don't get it on in British surf.' ${ }^{68}$ British waves were constantly compared with American and Australian waves, as noted in an interview with a Welsh surfer, 'If we had perfect waves here we wouldn't have to travel. We don't have perfect waves here so we have to travel. We're more inclined to travel than people in Australia with perfect waves on their doorstep, and also we travel for warmth.' The issue of climate is central to much British surfari narrative in the magazines analysed and could be argued as a crucial difference between British and American surfing cultures.

\section{Localism}

One consequence of overcrowding was in the issue of localism. Localism is founded upon the hierarchical order of who is allowed to take the wave in a given locality. The hierarchy preferences local, more competent surfers, followed by non-local competent surfers down to grommies (young beginners), knee boarders and bodysurfers vying for positions near the bottom. Surfers who transgressed the perceived hierarchy could be punished by being bullied off the waves or physically attacked. Localism problematised the notion of brotherly love in the surfing fraternity and was a constant concern of surfers in letters and articles in American magazines. John Romuno, for instance pleaded for more tolerance on the waves between board riders who stood up and kneeboarders in the pages of Surfer, 'We...[board riders and knee boarders]...must try to surf together, or we create a small Vietnam. ${ }^{69}$ However, the fact that kneeboarders were often dubbed 'cripples' and audiences at pure 
surfmovies often yelled, 'Stand up you pussy!' when a kneeboarder was shown, merely reinforced antagonism on the waves between board riders and kneeriders.

There is no evidence that British surfers resorted to violence in this era. Resistance to other surfers was articulated in subtler ways such as preventing 'other' surfers from discovering local (or European) surf spots or, by invoking national stereotypes, distancing from other nationalities by inferring foreigners were ill-mannered and impolite. British national identity and its expression through courtesy, manners and fair play reflected the stereotype of the English amateur gentleman sportsman and the self-sacrifice of the sporting hero was a typical British stereotype. ${ }^{70}$ The French were particularly targeted as an impolite and unsportsmanlike group. A trip to Seignosse, France, for instance, detailed a case of surf rage between French and British surfers. B.S. was the victim of overt localism where French surfers 'dropped in' on his waves. He commented, '...Y You sit out back patiently waiting for "your turn" but your turn never seems to come. Each time you take off there is another guy to your left. ${ }^{971}$ Localism has two different hierarchies, locals are preferred over non-locals, but if a non-local proves an expert surfer they will be respected. Unfortunately B.S. lost respect through his incompetence, worse: 'You realise perhaps your hesitancy is not entirely out of courtesy but also out of fear... ${ }^{, 72}$ Loss of respect due to showing fear is also an issue noted by Donnelly relating to rock climbing. ${ }^{73}$ Subsequently B.S. committed a cardinal sin in surfing of dropping in on another surfer's wave. He was rebuked by a French surfer and seethed, 'I haven't come all this way to be put off by a bunch of $* * * * * * *$ Froggies.' He was then approached by a group of French surfers and the leader orders him to "Gooo hooome!"' As rage and violence had no place in British sports he 'inwardly seethed,' demonstrating the 'superiority' of British 'character'. 


\section{Climate and realism}

The notion of climate and endurance as mentioned above by Newton, was a defining feature of British surfers' perception of their difference from American and other surfing nationals. Climate permeated nearly every surf narrative or article in British surfing magazines. However, the importance of inconsistent climate and terrain is problematic in traditional sports and athletics. Weiss,${ }^{74}$ for instance, identifies the difference between 'space' and 'place'. 'Space is neutral and uncontaminated by variables such as wind and temperature. 'Place' however, is culturally constructed. Weiss argues that sports should take place in 'spaces' rather than 'places' which will ensure that competition is fair. Surfing, in general, does not preference competition and the discussion of locations above indicates that surfers have a great affinity with certain places. Therefore it is interesting to note that British surfers defined and made meaning of the 'places' and their unique climates and terrain rather than the 'spaces' of surfing.

Endurance and bodily mortification were signs of dedication and British surfer authenticity. This was especially emphasised in interviews with Scottish surfers and those who surfed on the North East coast of England. Surfers in Scotland and the Northern regions of England who did not have ready access to British surfing infrastructure in the south had to rely on adapted diving suits and layers of jumpers. However, surfing cold waters was a badge of courage or foolhardiness. One surfer in Scarborough noted how he attempted to show off to some girls by surfing in February in the early seventies without his wetsuit 'and I nearly died of hypothermia. ${ }^{75}$ On an early trip surfing as a schoolboy, a Scottish surfer noted, 'There was a pavilion on the beach, the Beach Ballroom, the caretaker took pity on us and allowed us to warm ourselves on the brazier. Then we went back in the water again, but we could only 
stay in for ten to fifteen minutes. The waves were offshore slop. ${ }^{76}$ The coldest surfing session was at Pease Bay in which there was a six foot snow drift about a mile from the beach. That these surfers chose to continue surfing despite cold waters without wetsuits was a sign of British hardiness and grit. The problems of cold water were alleviated when wetsuits became available along the south coast through companies such as Bilbo, the European Surf Company and Tiki and could be purchased either by mail order or on holiday in Cornwall and Devon.

The sea temperature was not the only problem endured by British surfers. The problems of climate also were described in articles on surfaris as in a trip to South Wales, 'The rain is driving against the windscreen of the VW van as we head west. Outside the wet, dark green fields vanish into the mist as the van climbs the hills. Inside there is no talk. It is depressing to get up at $6.30 \mathrm{am}$ to find rain everywhere.' 77 As in descriptions of surfaris in other British surfing magazines, the depression was unabated when the waves were 'offshore mush' and despite driving around several beaches there is no decent surf, 'we feel sick to have come so far for such rough surf. ${ }^{78}$

In comparison, stories of surfing colder climates in Surfer and Surfing were uncommon. A story about surfing in Oregon for instance, which appeared in Surfer, described how, ' the water temperature demands enthusiasm...'tit-freezing water makes things pretty miserable. ${ }^{, 79}$ The article notes the miseries of surfing in the cold and the necessity for the surfer to be highly motivated. These issues are almost identical to the main themes of climate and water temperature in British surfing magazine rhetoric. The nearest accounts of like are a description of a trip to Europe by Jim Kempton for Surfer in 1978. Kempton described his trip to Spain which was the culmination of three attempts to find surf in that country. In his first trip, 1971: 
We only had rough directions on a map, and it was hard to find.

We spent about half a day taking roads that lead [sic] to the wrong place. It was raining and it was cold. When we got there the surf was flat. We spent a week in the place and never saw a wave. ${ }^{80}$

Once on the beach in 1978 , Kempton noted that the weather was, '... so cold it was hailing on the beach. Hailing! And if that doesn't blow you out, there was a guy surfing out there without a wetsuit. ${ }^{, 81}$ From this statement, so similar to British surf rhetoric, it is tempting to propose that the climate might have a great deal to do with expressions of British rhetoric in surfing. It is unlikely that if Kempton wrote his article for Surfer in 1971 that it would have been published. That he eventually got the article published in Surfer 1978 was possibly due to the eventual successful outcome of the trip.

\section{Realism and Adventure}

British surfing magazines promoted regional waves, encouraging surfers to explore their own coastline with tales of unexplored breaks and unknown waves. For instance an article in British Surfer praised Norfolk as a destination where, 'waves can be found to rival those of the West Coast in both size and shape', with the added attraction of, 'more breaks than surfers' ${ }^{82}$ The surfari was often represented as an escapade, for instance Bez Newton noted, 'A surfari is always an adventure - with its difficult moments and its stoking times... ${ }^{, 83}$ Many surfari narratives read like Boy's Own adventures with surfers exploring unknown territories and 'roughing it', camping. Often serendipitous meetings formed the basis of lifelong friendships. Surfers who explored the British coastline reported recognising other surfers from the surfboard on the car roof. As surfing was a relatively rare activity they would stop, exchange stories and might then go for a surf together. If the weather or waves were 
inclement, then they might go to the pub and arrange to surf another time. There were two types of resolution in surfari narrative; a disastrous surfari might end in an upbeat manner where a perfect break was discovered or the surfer joined up with other surfers for a night in the pub or else the surfer sat in either a tent or caravan eating inedible food and trying to stay warm.

One adventure in the mid seventies took place when Andy Bennetts, a Scottish surfer, went on holiday with his wife in the Cape Wrath area and Thurso in 1974 and found good waves. This resulted in, ‘...the best surf ever in the North that day, and I wondered if the sea would ever stop coming through' ${ }^{84}$ His trip was even more successful when on the next day he moved on to Fraserburgh, 'Imagine my surprise to find half a dozen guys out. We had a great time in three foot of glassy surf. Over a nip and a noggin with these guys later that evening I learnt that they have been surfing up there for four years... ${ }^{85}$ The meeting was the beginning of a long friendship and numerous friendly contests between the Edinburgh Surf Club and the Fraserburgh Surf Club. Such was the success of this trip that Bennetts proposed an adventure the following year to fully explore the Cape Wrath area. However, it would not be easy as the beaches were not accessible by road. This necessitated a trip across the Kyle of Durness on the ferry, then walking one and a half miles over moorland. Bennetts proposed the construction of, 'A device for carrying the boards, tent and other supplies would have to be made... what I have in mind is a rickshaw type device, using two bicycle wheels, which could be pulled over the moorland. ${ }^{96}$ Like American surfers Bennetts attempted to identify the type of wave in the only way other Scottish surfers would recognise, likening it to one known by all the Edinburgh surfers noting that it is 'like a Pease Bay setup, with rocks on the right of the beach, and... about a four foot swell breaking right and left off the centre of the beach. ${ }^{97}$ 
However, not all adventures were successful or romantic. Some of the journeys described in Surf were either dismal, comic or pedantic accounts of the minutiae of the journey. Nevertheless, this realistic description of a surfing trip was often regarded as an adventure. In the 'Impressions' series account of surfing adventures were often upbeat and might include some comedic situations of end on a lighter note. In one surfari to Roscoff for instance, a group of surfers missed the ferry at Plymouth so they spent the night camping in a forest near Plymouth. In the moring they visited Bantham where it rained. However, the potentially disastrous trip was saved with the discovery of an unknown break in Salcombe. Despite one of the party being injured on rocks the surfari was considered a success because of the experience of surfing the tube. This resulted in a '...state of near-drunkenness which follows a surf like this..., ${ }^{88}$ Newton concluded with a typical hippie statement, 'You'll find infinity down the narrowest lanes, across the muddiest fields, over the most precipitous cliffs, at the end of a rainbow!'

To counteract this optimistic type of surfari narrative, Surf also ran a series entitled, 'Truckin'. 'Trucking' aimed to be 'factual...we intentionally do not paint the rosy picture we so often do in our Impressions section... ${ }^{89}$ The articles were aimed at those who wished to 'see how the other half lives', those who wanted realistic information, those who may have been duped by unrealistic reports were provided with facts 'dispelling the romantic myth' and the article looked favourably on, 'Those of spirit and adventure who see tough spots like Bali as a challenge and probably glean some little information about what they are in for and how to deal with it. 90 This series, therefore aimed to confound fantasy expectations and provide the challenge of adventure despite such exotic destinations as Portugal, Morocco and Bali. The description of the trip to Morocco went into the relative costs of flights ( $£ 70$ 
to Tangier or direct to Agadir for $£ 105$ return) or ferry (a mini with six passengers $£ 9.75$ one way). In the latter travellers were given information on inoculation, costs of taxi-buses from the airport, tourist scams, food and drink ('Do not buy meat...don't eat too much fruit.') and disease 'Malaria was prevalent - as many as fourteen people a day died from it on Bali alone.'

Much of the rhetoric of the surfari in these narratives, tended to be tempered by a set of ritual hardships, a mortification of the flesh, whether it was rain, bodily injury or transport problems. Even the local terrain, often described in lyrical terms in 'pure' surf films, presented danger, 'You have to walk over a mile through a cactus-lined path to reach Ulluwatu...It looked very romantic in Morning of the Earth, but spiky cactus can be pretty tough on bare flesh.' The scepticism afforded to Albert Falzon's pure surf film, Morning of the Earth demonstrates the necessity of tempering the romantic myth of the surfari in foreign climes. Readers were also informed of the dangers of poisoning on the coral reef. There was a list of 'dos' and 'don'ts' to stay on the right side of the law or officialdom, 'an offhand answer to an uncivilly-put question may result in long delays, on-the-spot-fines, or being thrown into a feelthy [sic] Moroccan jail. ${ }^{91}$

A description of a surf trip with the coda of the 'miserable camping supper' was described in a trip to Morocco, 'By nightfall the slight off-shores that were feathering the tops this morning have turned South South West, bringing rain with them. You sit huddled in the tent over a lukewarm supper of sardines, Cadbury's Smash and rehydrated beans... ${ }^{92}$ Realistic or downbeat accounts of surfaris are rarely found in American and Australian surf magazines in this era. For instance, a comparison of a surfari to ride 'Bruce's Beauties', named after Bruce Brown's perfect wave at Cape St. Francis, South Africa which he claims is constant every day of every year, differs 
in Surfer and Surf. The report for Surfer by British surfing champion, Rod Sumpter declares that surfers enjoyed perfect surfing for four days, 'We're so lucky it's insane. Cape St. Francis simply doesn't work often, and we had it the best it's been for a long time. Locals say it works twice a year on good years'. ${ }^{93}$ Sumpter was writing for an American market and may therefore have adapted his rhetoric to empathise with American optimism. Whereas Brown in The Endless Summer asserted the waves were perfect '365 days of the year, every year', Sumpter was hesitant claiming they are the 'best they have been for a long time'. Bruce Brown and Rod Sumpter had a different experience from British surfers who turned up only to find, 'For ten days the wind has been onshore and the weather cold. Today the wind has turned offshore. We all sit and wait for the elusive south swell but it doesn't show. ${ }^{, 94}$ Despite this initial hardship, later tubes begin to form. However, this was not the end of their trials, for in their impatience to surf they took off together and 'end up in a tangle of arms, legs and boards. My fin is stuck in the bottom of Murray's board. We are both cursing. 95

\section{Conclusion}

The type of waves British surfers surfed and the freezing cold had a huge impact on surf rhetoric. Why the British should choose to express their differences from other surfing nations such as the Americans, Australians and French as an internalised victim hood may have been the result of the climate, water temperature and the perceived national character with its need to 'tell it like it is.' So where American surfers romanticised surf lifestyles in this era, British surfers could not wholeheartedly agree that surfing was a comfortable activity. The fantasy lifestyle was stretched further in American soul surfing rhetoric with its descriptions of waves as altered states, crystal caves and green room shingles. Some British surfers, mainly from the South coast with its warmer waters, attempted to emulate green room writing, but as 
Andy Bennetts noted, they could not totally adopt taking drugs and the hippie lifestyle because the North Sea was 'just too damn cold.' The amateur sportsman ethic proposed by Mangan might also be a factor in understanding British national surfing identities. Finally, it is worth reflecting that the cold waters and climate had a great affect on the way surf values developed within local conditions. The neutral spaces which Weiss proposes as desirable because they ensure a standardisation of experience, are problematized in this examination of British surfing. British surfer identity is predicated on location and climate as the defining features of British surfers' identities. Perhaps climate, place and national identities might bear further investigation. These local conditions are responsible in part for the ways that global texts are hybridised and adapted to local conditions. 
${ }^{1}$ The author wishes to thank the surfers interviewed for their enthusiasm and support for the project, the reviewer for his/her useful comments, also Helen Bowman from Manchester Metropolitan University for her advice and encouragement.

2 Nick Ford and David Brown, Surfing and Social Theory: experience, embodiment and narrative of the dream glide (London and New York, 2006), p.48.

3 James Maguire, Global Sport: Identities, Societies, Civilizations. (Cambridge, Oxford, Malden, 1999).

4 Arjun Appadurai, 'Disjuncture and difference in the global cultural economy', Public Culture, 2 (2), pp.1-24..

5 Beck (2000), p.54.

6 Joan Ormrod, Expressions of nation and place in British surfing identities. (PhD. thesis, Manchester Metropolitan, 2006).

7 Colin Campbell, The Romantic Ethic and the Spirit of Modern Consumerism (Oxford, 1987), p.78.

8 Jon Stratton, 'On the importance of subcultural origins (1985)', in Ken Gelder and Sarah Thornton, eds., The subcultures reader (London, New York, 1997), pp.181-90.

9 R.L. Rutsky, 'Surfing the Other: ideology on the beach', Film Quarterly, 52 (4) (1999) pp.12-23; Gary Morris, 'Beyond the beach: social and formal aspects of AIP's Beach Party movies.' Journal of Popular Film and Television, 23 (2) (1993) pp.2-11; Ormrod, J., 'Issues of Gender in Muscle Beach Party (1964)', Scope an Online Journal of Film Studies, (2002).

http://www.nottingham.ac.uk/film/journal/articles/muscle-beach.htm; Douglas Booth, Australian beach cultures: the history of sun, sand, and surf (London, 2001).

10 Jon Stratton, 'On the importance of subcultural origins (1985)', p.184.

11 Douglas Booth, 'Surfing films and videos: adolescent fun, alternative lifestyle, adventure industry', Journal of Sport History, 23 (3) (1996), pp.309-327.

12 Dean Scheibel, '"Making waves" with Burke: surf Nazi culture and the rhetoric of localism'. Western Journal of Communication, 59, (1995), pp.253-269.

13 Rod Holmes and Doug Wilson, The Roots of British Surfing (Cornwall, 1994), p.9.

14 Scheibel, “"Making Waves” with Burke', 253-269. 
15 Ibid.; Ricky Farmer, ‘Surfing: Motivations, Values, and Culture', Journal of Sport Behaviour, 15 (3), (1992), pp.241-257.

16 Margaret Henderson, 'Some Tales of Two Mags: Sports Magazines as Glossy Reservoirs of Male Fantasy',Journal of Australian Studies, (62) (1999), pp. 64-75, 245-47; Idem, 'A Shifting Line Up: men, women, and Tracks surfing magazine', Continuum: Journal of Media and Cultural Studies, 15 (3) (2001), pp.319-332; Belinda Wheaton, 'New lads?' Masculinities and the New Sport Participant. Men and Masculinities, 2 (4) (2000) pp.436-458.

17 Belinda Wheaton and Becky Beal, “Keeping it Real” Subcultural Media and the Discourses of Authenticity in Alternative Sports', International Review for the Sociology of Sport, 38 (2) (2003), pp.155-76.

18 Thomson, Surfing in Great Britain, p.253.

19 Matt Warshaw, Surfriders: In Search of the Perfect Wave, (Del Mat, 1997), p.38.

20 Idem., The Perfect Day: 40 years of Surfer magazine, (San Francisco: 2001), p.8.

21 Chris Carter. 'One from the heart', Surfing, 20 (3) (1984), p. 38.

22 Ibid., p. 44.

23 Douglas Booth, 'Expression sessions: surfing, style and prestige', in Robert E. Rinehart and Synthia Sydnor, eds., To the Extreme: alternative sports, inside and out (New York, 2003), p.319.

24 Stuart Hall, 'Encoding/decoding', in Paul Marris and Sue Thornham, eds., Media Studies: a Reader (Edinburgh, 1996), pp.135-137.

25 Thomson, Surfing in Great Britain, p.255.

$26 \operatorname{Surf} 4$ (4), (1974), p28.

27 Ibid.

28 Ibid.

29 Richard Mills, The Young Outsiders: a study of alternative communities (London, 1973).

30 Timothy Miller, The Hippies and American Values (Knoxville, 1991).

31 Booth, Australian beach cultures, p.112; Miller, The Hippies.

32 Mike Brake, Comparative youth culture: The sociology of youth culture and youth subcultures: sex and drugs and rock ' $n$ ' roll (London, Boston, 1990).

33 Ibid., pp.99-102.

34 Ibid. p.100. 
35 John Durward, 'Surfing and the artistic decision', Surfer, 11 (2) (1970), pp.100-102.

36 Douglas Booth, 'Surf lifesavers and surfers', in John Bale and Patricia Vertinsky, Sites of sport : space, place, experience (London, New York: 2004) p.123.

37 Drew Kampion, Stoked: a history of surf culture (Köln, 1998), p.127.

38 Matt Warshaw, The encyclopedia of surfing (Orlando, 2003).

39 Nat Young, Nat's Nat and that's that: a surfing legend (Angourie, 1998).

40 Gary Crandall, 'Potato chip Thrills in a Washing Machine', Surfer, 11 (2) (1970), p.112.

41 Drew Kampion, 'In the Pope's Living Room with Jock Sutherland', Surfer, 11 (6) (1970), p.72.

42 The Mad General, 'Letters', Surfer, 11 (2) (1970), p.16.

43 Steve Pezman, 'The essence of a moment', Surfing, 2 (2) (1969), p.36.

44 Denny Aaberg, 'Invisible Tracks,' Surfer, (2) (1970) p.77.

45 Scheibel, ‘"Making waves” with Burke', pp.253-269; Booth, 'Expression sessions', pp.315-36;

Robert Preston-Whyte, 'Constructions of surfing space at Durban, South Africa.' In Tourism

Geographies, 4 (3) (2002), pp.307-328; Nat Young, Surf Rage: a surfer's guide to turning negatives into positives, (Angourie, NSW, Australia: 2001).

46 Bez Newton, 'Interview: Roger Mansfield', Surf, 5 (3) (1975), p.10.

47 S. Lyng, 'Edgework: A Social Psychological Analysis of Voluntary Risk Taking.' American Journal of Sociology, 95 (4), (1990), pp.851-886; Mark Stranger The Aesthetics of Risk: A Study of Surfing.

International Review for the Sociology of Sport, 34 (3) (1999), pp.265-276.

48 Steve Harewood, 'Manufacturer's Forum, no. 3: Surfing', Surf, 4 (7) (1974), p.16.

49 Ibid.

50 Interview Andy, Musselborough, Scotland.

51 Ibid., p.13.

52 Judith Harrison, letter, British Surfer, 1(3) (1969), p.30.

53 Bez Newton, ‘Editorial', Surf 4 (8) (1974), p. 3.

54 Bez Newton, ‘Waves', Surf, 5 (3) (1975), p.4.

55 Bryan H. Farrell, Hawaii, the legend that sells (Honolulu, 1982).

56 Booth, 'Surfing Films and Videos', pp.309-327.

57 Joan Ormrod, 'Endless Summer (1964): consuming waves and surfing the frontier', Film and History, 35 (1) (2005), pp.39-51. 
58 Scheibel, "'Making Waves" with Burke', pp.253-269.

59 Bill Cleary, Surfer, 6 (4) (1965), in Warshaw, The Perfect Day, p.16.

60 Matt Warshaw Surfriders: In Search of the Perfect Wave (California, 1997), p.43.

61 Thomson, Surfing in Great Britain, p.288-9.

62 Advert. British Surfer, 1 (2) 1969, p.25.

63 Unknown, ‘Mehdia-Plage, Morocco', Surf, 4 (7) (1974), p.8.

64 Booth, Australian Beach Cultures, p.99.

65 Chris Hinds, 'Newquay’ British Surfer, 1(1) (1969), p.9.

66 Bez Newton, 'Interview no. 12: Roger Mansfield', Surf, 4 (7) (1974), p.4.

67 Trevor Gough, 'Places: That Place in Spain', Surf 6 (2) (1976), p.12.

68 Bez Newton, 'Interview no.11: John Cartwright', Surf, 4 (6) (1974), pp.9-12.

69 John Ramuno, ‘Kneeboarders and board surfers: someday brothers', Surfer, 12 (6) 1971, p.37.

70 J. A. Mangan, ed., Tribal identities: nationalism, Europe, sport (London, 1996).

71 B.S., 'France was Never Like This. Dateline: Seignosse, early October', Surf, 4 (7) (1974), p.18. 72 Ibid.

73 Peter Donnelly and Kevin Young, 'The construction and confirmation of identity in sport subcultures', in A. Yiannakis and M.J. Melnick eds., Contemporary issues in the sociology of sport (Champaign, Il, 2001), 399-412.

74 Oscar Weiss, 'Identity reinforcement in sport, revisiting the symbolic interactionist legacy.'

International Review for the Sociology of Sport, 36 (4)(2001), pp.393-405.

75 Interview, Tony, Scarborough.

76 Interview, Ian, Musselborough, Scotland.

77 Paul Thomas, ‘The far west.’ British Surfer, 1 (5) (1969), p.4.

78 Ibid.

79 Bert Moffatt, 'Oregon as we like it.' Surfer, 13 (2) (1972), p.75.

80 Jim Kempton, ‘Sketches of Spain’, Surfer, 19 (5) (1978), p.28.

81 Ibid., p.32.

82 Author unknown, 'Think of Norfolk and what picture comes up?' British Surfer, 1 (6) (1969), p.18.

83 Bez Newton, "Trucking: Morocco." Surf, 4 (7) (1974), p.22.

84 Andy Bennetts Surf October 1975:3. 
85 Idem., 'Impressions 7: Scotland - Oz', Surf, 4 (8), (1974), p.9.

86 Ibid., pp.8-9

87 Ibid.

88 Bez Newton, 'Impressions: ‘At the end of the rainbow', Dateline 'Infinity' South Devon, Early

October', Surf 4 (7) (1974), p.13.

89 Bez Newton, "Trucking: Morocco." Surf, 4 (7) (1974), p.22.

90 RMc Surf, 5 (3) (1975), p.26.

91 Ibid.p.21.

92 Unknown, 'Mehdia-Plage, Morocco', Surf, 4 (7) (1974), p.8.

93 Rod Sumpter, (1969). ‘Cape Beauties', Surfer, 10 (1) (1969), p.48.

94 Phil Clifford, 'Impressions. Dateline: Bruce's Beauties, Cape St. Francis, Natal, March 1974’, Surf, 4

(6) (1974), p.5.

95 Ibid. 